\title{
Control of Wind-Induced Vibration of Transmission Tower-Line System by Using a Spring Pendulum
}

\author{
Peng Zhang, Liang Ren, Hongnan Li, Ziguang Jia, and Tao Jiang \\ Faculty of Infrastructure Engineering, Dalian University of Technology, Dalian, Liaoning 116024, China \\ Correspondence should be addressed to Peng Zhang; peng1618@163.com
}

Received 23 October 2014; Revised 12 February 2015; Accepted 12 February 2015

Academic Editor: Massimo Scalia

Copyright (C) 2015 Peng Zhang et al. This is an open access article distributed under the Creative Commons Attribution License, which permits unrestricted use, distribution, and reproduction in any medium, provided the original work is properly cited.

\begin{abstract}
The high-voltage power transmission tower-line system, which is a high flexible structure, is very susceptible to the wind-induced vibrations. This paper proposes the utilization of the internal resonance feature of the spring pendulum to reduce the wind-induced vibration of a transmission tower. The kinetic expression of the spring pendulum system is obtained through Lagrangian equation. The condition of the internal resonance is verified to be $\lambda=2$, in which $\lambda$ is the ratio of the spring mode frequency over the pendulum mode frequency. A $55 \mathrm{~m}$ tower in the Liaoning province is established in SAP2000 to numerically verify the effectiveness of the proposed device. The spring pendulum is modeled using Link element. The wind speed history is generated based on Kaimal spectrum using harmonic superposition method. Results show that, (1) compared with the suspended mass pendulum, the spring pendulum absorbs more energy and reduces the oscillation more effectively and (2) the vibration control performance of the proposed spring pendulum improves as the external wind load increases.
\end{abstract}

\section{Introduction}

The high-voltage transmission tower-line system is a vital facility in the power transmission system. However, the transmission tower-line system generally has low frequencies and damping ratios associated with their fundamental oscillation modes, and when subjected to wind loads, it may experience large amplitudes of oscillation [1]. Recent investigations have reported several tower failures due to strong wind excitations $[2,3]$. Failures of the transmission tower-line system may cause massive blackouts, resulting in major direct and indirect consequences on the economy and national security [4]. It is of great importance to reduce the vibrational response and improve the reliability of power transmission towers under wind loads.

During the past two decades, many researchers and engineers have paid much attention to this issue and proposed many techniques to improve the wind-resistance of the transmission towers [5]. Conventional techniques aim at increasing the stiffness of the transmission tower by enlarging the cross-section area of the steel members or shortening the effective member length by adding additional members. These methods will tremendously increase the project cost and thus are not financially acceptable [2]. An alternative approach to prevent the catastrophic damage of transmission tower is to install vibration control devices $[5,6]$.

The vibration control devices for vibration control of transmission towers can be divided into two categories. One category aims at increasing the damping ratio by incorporating energy dissipating dampers, such as frictiontype reinforcing members $[2,7,8]$, magnetorheological (MR) dampers [9], viscoelastic dampers (VED) [10], lead viscoelastic dampers (LVED) [11, 12], and giant magnetostrictive material (GMM) actuators [13].

The other category involves attaching a linear dynamic absorber to the tower. Kilroe [14] installed vibration absorbers on members of tower arms to mitigate the fatigue phenomena. Battista et al. [15] proposed a pendulum-like damper, which reached reduction efficiency of over $90 \%$ with the first mode of vibration. Liu and Li [16] combined the linear spring model and the Maxwell model to simulate the tuned mass damper (TMD) in a 3D tower model. Numerical results showed that the vibrational response was reduced by $17 \%$ with optimal design. He et al. [17] proposed a suspended mass pendulum (SMP) for vibration reduction of a transmission tower. Both numerical and 
experimental results verified that the SMP was very effective in reducing acceleration of the tower. These absorbers are all linear absorbers. Introducing nonlinearity may improve the vibration control performance.

Recently, nonlinear vibration absorbers have been developed in a related field of vibration control of buildings. The nonlinear attachments can localize the vibration energy in a one-way, irreversible fashion $[18,19]$. This phenomenon is called nonlinear energy sink (NES). Compared with the traditional linear dynamic absorber, NES has a wider effective frequency band and better vibration reduction performance $[18,19]$. The NES can be achieved in many ways, such as incorporating a nonlinear cubic spring [19], incorporating collisions [20], or incorporating the internal resonance [21].

The spring pendulum (SP) which is basically a mass suspended by a spring can be regarded as a combination of a simple pendulum and a spring oscillator [22, 23]. It has two modes of vibrations, the pendulum mode and the spring mode. When the SP is correctly designed, the two vibration modes will be strongly coupled, and vibration energy can be transmitted between the two modes. This is called internal resonance, and because of this internal resonance feature the SP can be designed as a new type of NES for vibration control of power transmission tower-line systems.

In this paper, the SP is proposed as a new type of NES to improve the wind-resistant performance of the transmission tower-line system. In Section 2, the kinetic expression of the SP will be obtained through Lagrangian equation. The internal resonance feature will be discussed and the optimal design of a SP will be given. In Section 3, a multimass model of a practical transmission tower will be established to numerically verify the effectiveness of the SP. The wind field will be simulated using superposition method based on Kaimal spectrum. The numerical results will be presented in Section 4. Compared with the traditional SMP, the SP absorbs more energy and reduces the oscillation more effectively. Moreover, the intensity of the wind load will be varied to investigate its influence on the vibration control performance in this section.

\section{Mechanism of the Spring Pendulum}

2.1. Mathematical Model of a SP. As shown in Figure 1, the SP is basically a mass block suspended by a linear spring. The motion equation can be derived through Lagrangian equation. In Figure $1, k_{s}$ denotes the stiffness of the spring, $l_{\text {ori }}$ is the original length of the spring, $l_{0}$ is the length under gravity load, and $m_{p}$ is the mass of the mass block. Therefore,

$$
l_{\text {ori }}=l_{0}-\frac{m_{p} g}{k_{s}} .
$$

Establishing a rectangular coordinate at the center of the mass block, $x_{p}$ and $y_{p}$ denote the displacements of the mass block in the two directions. Correspondingly, $\dot{x}_{p}, \dot{y}_{p}, \ddot{x}_{p}$, and

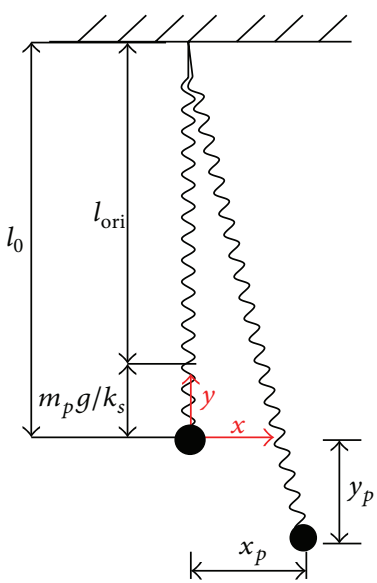

FIgURE 1: Schematic of the spring pendulum.

$\ddot{y}_{p}$ are the velocity and acceleration. The total kinetic energy and potential energy are

$$
\begin{aligned}
& V=\frac{1}{2} k_{s}\left(\sqrt{x_{p}^{2}+\left(l_{0}+y_{p}\right)^{2}}-l_{\text {ori }}\right)^{2}-m_{p} g y_{p}, \\
& T=\frac{1}{2} m_{p} \dot{x}_{p}{ }^{2}+\frac{1}{2} m \dot{y}_{p}{ }^{2} .
\end{aligned}
$$

Substitute (2) into the Lagrangian equation, and the motion equation can be obtained as follows:

$$
\begin{aligned}
& \ddot{x}_{p}=-\frac{k_{s}}{m_{p}} x_{p}\left(1-\frac{l_{\text {ori }}}{\sqrt{x_{p}^{2}+\left(l_{0}+y_{p}\right)^{2}}}\right), \\
& \ddot{y}_{p}=g-\frac{k_{s}}{m_{p}} y_{p}\left(1-\frac{l_{\text {ori }}}{\sqrt{x_{p}^{2}+\left(l_{0}+y_{p}\right)^{2}}}\right) .
\end{aligned}
$$

At any moment, the forces on the mass block in the two directions are

$$
\begin{aligned}
& f_{x}=k_{s} x_{p}\left(1-\frac{l_{\text {ori }}}{\sqrt{x_{p}^{2}+\left(l_{0}+y_{p}\right)^{2}}}\right), \\
& f_{y}=k_{s} y_{p}\left(1-\frac{l_{\text {ori }}}{\sqrt{x_{p}^{2}+\left(l_{0}+y_{p}\right)^{2}}}\right)-m_{p} g .
\end{aligned}
$$

2.2. Internal Resonance Feature of the SP. The SP has two vibration modes: the spring mode and pendulum mode. Define $\lambda$ as the ratio of natural frequencies of the two vibrating modes. Consider

$$
\lambda=\frac{\omega_{s}}{\omega_{p}}=\sqrt{\frac{k_{s} / m_{p}}{g / l_{0}}}=\sqrt{1+\frac{k_{s} l_{\text {ori }}}{m_{p} g}},
$$


where $\omega_{s}$ and $\omega_{p}$ are the circular frequencies of the spring mode and pendulum mode.

According to the literature [22], if $\lambda=2$, the spring mode and the pendulum mode will be strongly coupled and the kinetic energy will be transferred between those two modes. Figure 2 presents the locus diagram of a SP $\left(m_{p}=0.0485 \mathrm{~kg}, k_{s}=2.3 \mathrm{~N} / \mathrm{m}\right.$, and $\left.l_{\text {ori }}=0.82 \mathrm{~m}\right)$. The locus diagram agrees well with the results of the literature [22]. As shown in Figure 2, the suspended mass initially swings as a pendulum; the kinetic energy is mostly in the pendulum mode. After several periods, the kinetic energy is transmitted to the spring mode and the vibration of the mass is mostly in the vertical direction like a simple springmass oscillator. This phenomenon, which is named internal resonance, can enlarge the energy absorbing ability of the pendulum. Therefore, SP is more effective in reducing the vibration than a regular SMP.

2.3. One DOF Structure Controlled by a SP. Figure 3 shows a one-degree of freedom (DOF) structure controlled by a SP. Its equation of motion can be written as follows:

$$
m \ddot{x}+c \dot{x}+k x=F+f_{x},
$$

where $m, c$, and $k$ are the mass, damping, and stiffness of the primary structure, $\ddot{x}, \dot{x}$, and $x$ are the acceleration, velocity, and displacement, $F$ denotes the loading force, and $f_{x}$ is the restoring force generated by the SP. $f_{x}$ can be calculated by (4). Substitute (4) into (6), and (6) can be expressed as follows:

$$
m \ddot{x}+c \dot{x}+k x+\alpha_{\text {geo }} k_{s}\left(x_{p}-x\right)=F,
$$

where

$$
\alpha_{\text {geo }}=\left(1-\frac{l_{\text {ori }}}{\sqrt{\left(x_{p}-x\right)^{2}+\left(l_{0}+y_{p}\right)^{2}}}\right) .
$$

It can be easily verified that $\alpha_{\text {geo }}>0$. Therefore, the SP added a nonlinear spring to the primary structure. This nonlinear spring can reduce the vibration of the primary structure.

The vibration control mechanism of the SP can also be explained in terms of energy. The SP has two vibration modes, the pendulum mode and the spring mode. It can absorb the kinetic energy of the primary structure to the pendulum mode thus reducing the vibration of the primary structure. In this case, the SP works like a regular SMP. Moreover, the kinetic energy of the pendulum mode can also be transmitted into the spring mode. Therefore, the SP has larger energy absorbing ability than the regular SMP and is more effective in vibration control than the SMP.

2.4. Optimal Design of the SP. Two conditions should be satisfied in order to achieve the optimal design of the SP. One condition is that the frequency of the pendulum mode matches the frequency of the primary structure to be controlled; that is, $f_{p}=f_{\text {primary }}$. Here, $f_{p}$ and $f_{\text {primary }}$ are the frequency of the spring pendulum and the primary structure.

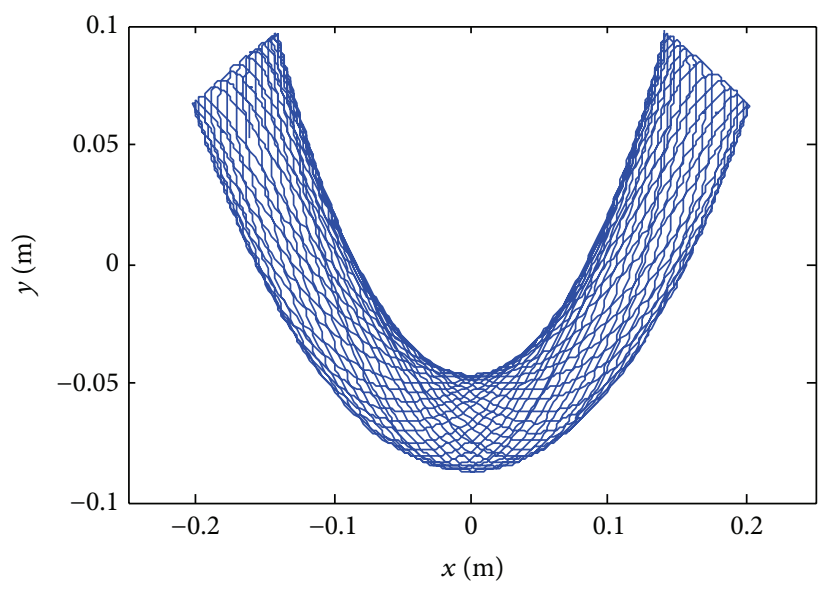

FIgURE 2: Locus of the mass, $\lambda=2$.

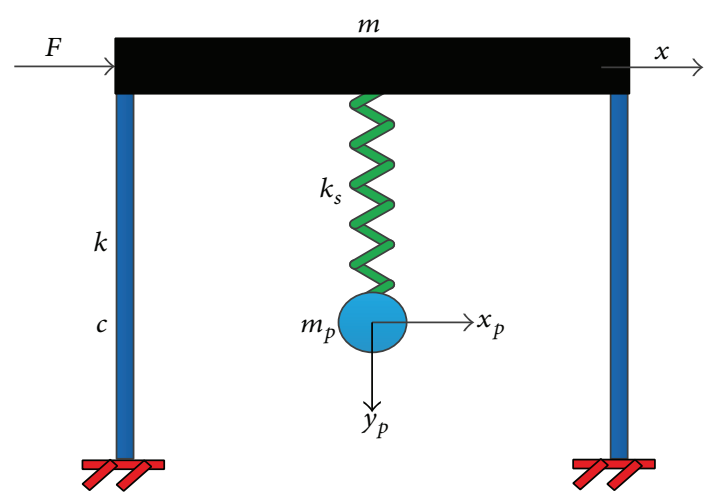

FIGURE 3: Schematic of one DOF system controlled by a spring pendulum.
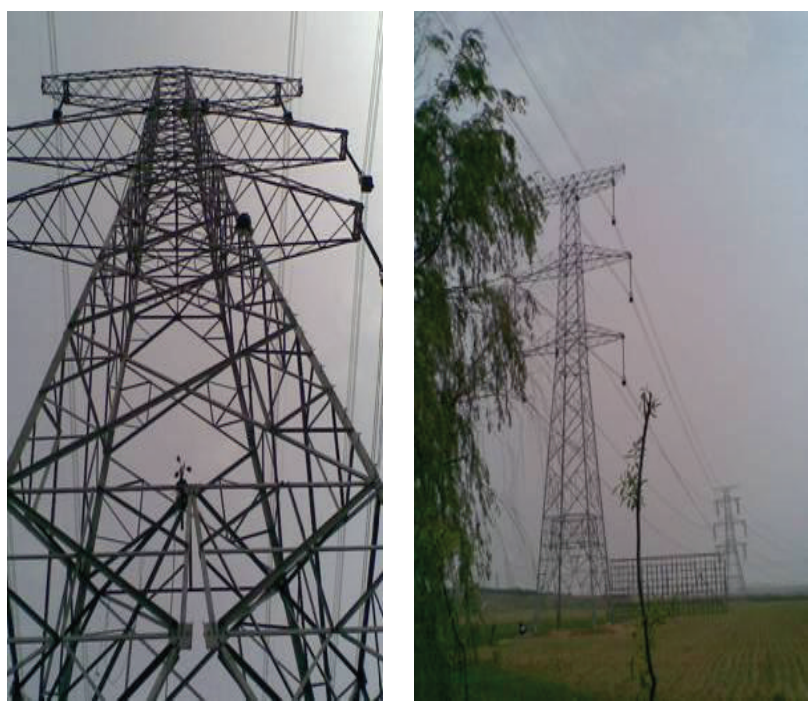

FIGURE 4: SZ21-type tangent transmission tower in Liaoning province. 


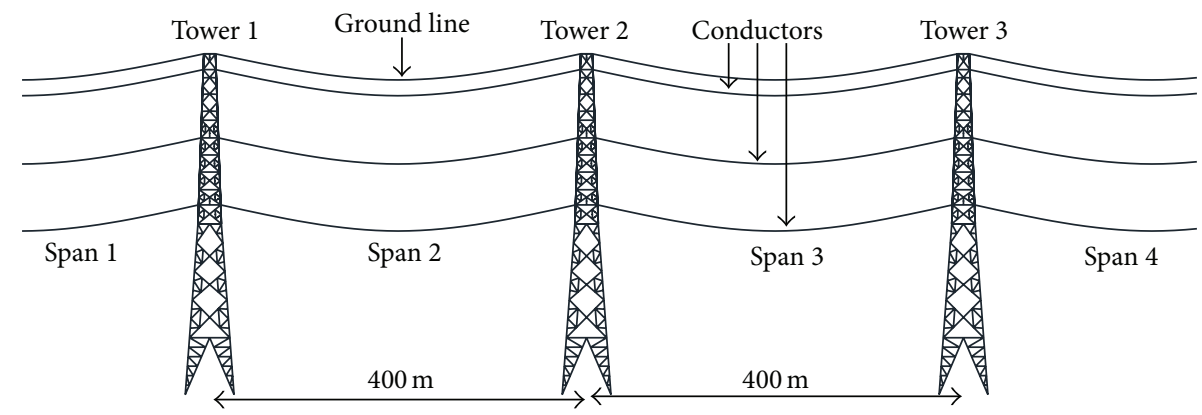

FIgURE 5: Transmission tower-line system.

Since the frequency of the pendulum mode is determined by the length of the spring $l_{\text {ori }}, l_{\text {ori }}$ should be determined as follows:

$$
l_{\text {ori }}=\frac{g}{(2 \pi f)^{2}},
$$

where $g$ is the gravitational acceleration.

The other condition to be satisfied is that $\lambda=2$. Then (5) can be written as follows:

$$
\lambda=\sqrt{1+\frac{k_{s} l_{\text {ori }}}{m_{p} g}}=2 .
$$

Therefore,

$$
k_{s}=\frac{3 m_{p} g}{l_{\text {ori }}},
$$

where $k_{s}$ is the stiffness of the spring, $m_{p}$ is the mass of the $\mathrm{SP}$, and $l_{\text {ori }}$ is the length of the spring.

\section{Numerical Model of the Transmission Tower-Line System Controlled by SP}

3.1. Prototype and the FEM Model of the Transmission TowerLine System. In order to verify the vibration control effectiveness of the proposed SP, a practical transmission tower-line system illustrated in Figures 4 and 5 is chosen as the primary structure to be controlled. The tangent tower is constructed of Q345 angle steels. Its height is $53.9 \mathrm{~m}$. The power transmission tower-line system includes three towers and four span lines as shown in Figure 4. The distance between adjacent towers is $400 \mathrm{~m}$. The upper 8 cables are ground lines and lower 24 cables are four-bundled conductor lines. The properties of the conductor line and ground line properties are listed in Table 1.

The transmission tower-line system is established in a FEM software, SAP2000. The angle steels of the tower and the isolators are modeled using Beam element; the conductor/ground lines are modeled using Cable element. The base points of the transmission tower are fixed on the ground. The connections between transmission towers and lines are hinged.

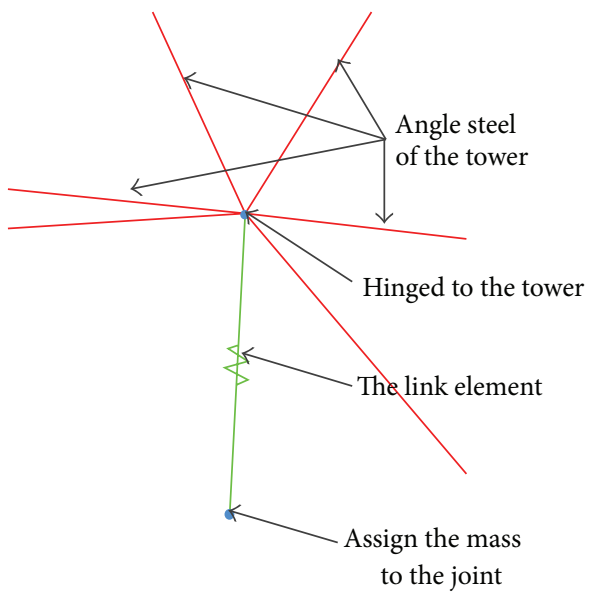

FIGURE 6: Simulating the SP using Link element in SAP2000.

TABLE 1: Conductor line and ground line properties.

\begin{tabular}{lcc}
\hline & Conductor line & Ground line \\
\hline Type & LGJ-400/35 & LGJ-95/55 \\
Outside diameter $(\mathrm{mm})$ & 26.82 & 16 \\
Modulus $(\mathrm{GPa})$ & 65 & 105 \\
Cross-section $\left(\mathrm{mm}^{2}\right)$ & 425.24 & 152.81 \\
Mass per unit length $(\mathrm{Kg} / \mathrm{m})$ & 1.3490 & 0.6967 \\
\hline
\end{tabular}

3.2. Modeling the SP in SAP2000. The SP is simulated by Link element in SAP2000, as shown in Figure 6. Length and stiffness of the Link element are calculated using (9) and (11). One joint of the Link element is hinged to the tower to be controlled. Mass of the SP is assigned to the other joint of the Link element. Figure 7 shows the locus of a spring pendulum calculated by SAP2000. The curve attained by SAP2000 is in good accordance with the theoretical results. Therefore, the Link element can be used to simulate the behavior of the SP.

3.3. Simulation of Wind Field. In wind engineering, the total wind velocity can be simulated as the sum of the mean velocity and the fluctuating wind velocity:

$$
v(z, t)=\bar{v}(z)+v_{f}(z, t),
$$




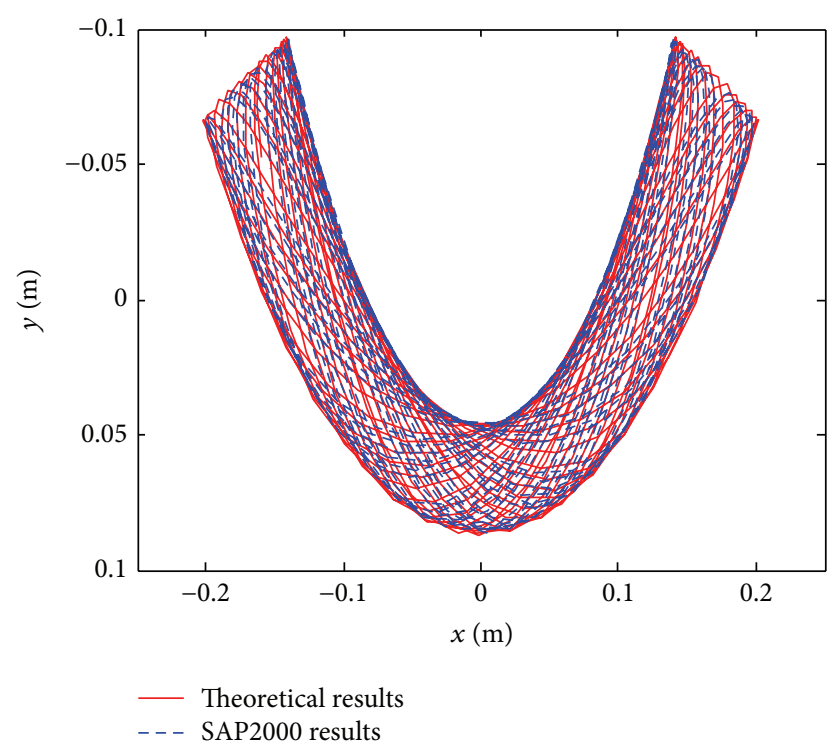

FIGURE 7: Locus of a SP calculated by SAP2000.

where $v(z, t)$ is the total wind velocity, $\bar{v}(z)$ is the mean wind velocity, and $v_{f}(z, t)$ denotes the fluctuating wind velocity.

According to the statistic data, the mean wind is often expressed by logarithmic function or exponent function associated with the height [24]:

$$
\bar{v}(z)=\frac{1}{k} u_{*} \ln \left(\frac{z}{z_{0}}\right),
$$

where $\bar{v}(z)$ is the mean wind speed of height $z, k$ is Karman constant, $z_{0}$ is the ground roughness length, and $u_{\times}$is friction velocity.

The time history of the fluctuating wind can be regarded as a random process with a specific power spectrum. According to the theory presented by Shinozuka and Jan [25], the fluctuating wind can be simulated using harmony superposition method:

$$
\begin{array}{r}
u_{i}(t)=\sqrt{2 \Delta \omega} \sum_{l=1}^{i} \sum_{k=1}^{N}\left|H_{i j}\left(\omega_{k}\right)\right| \cos \left[\omega_{k} t-\theta_{i l}\left(\omega_{k}\right)+\varphi_{l k}\right], \\
i=1,2, \ldots, m,
\end{array}
$$

where $u_{i}(t)$ is the time history of the fluctuating wind. $\Delta \omega$ is the frequency increment calculated by $\Delta \omega=\omega_{u p} / N$, in which $N$ denotes the division number and $\omega_{u p}$ is the cutoff frequency of calculation. $H_{i j}$ is obtained from Cholescky decomposition of the wind cross-spectral density matrix; $\theta_{i l}$ is the phase angle of structure between the two different load points; $\varphi_{l k}$ denotes the random phase distributed in the range of $[0,2 \pi]$.

Based on the central limitation theorem, the random process $u_{i}(t)$ will gradually tend to be the Gauss process when $N \rightarrow+\infty$. And the time interval should meet the requirement of $\Delta t \leq 2 \pi / 2 \omega_{u p}$ [26]. In this paper, they are

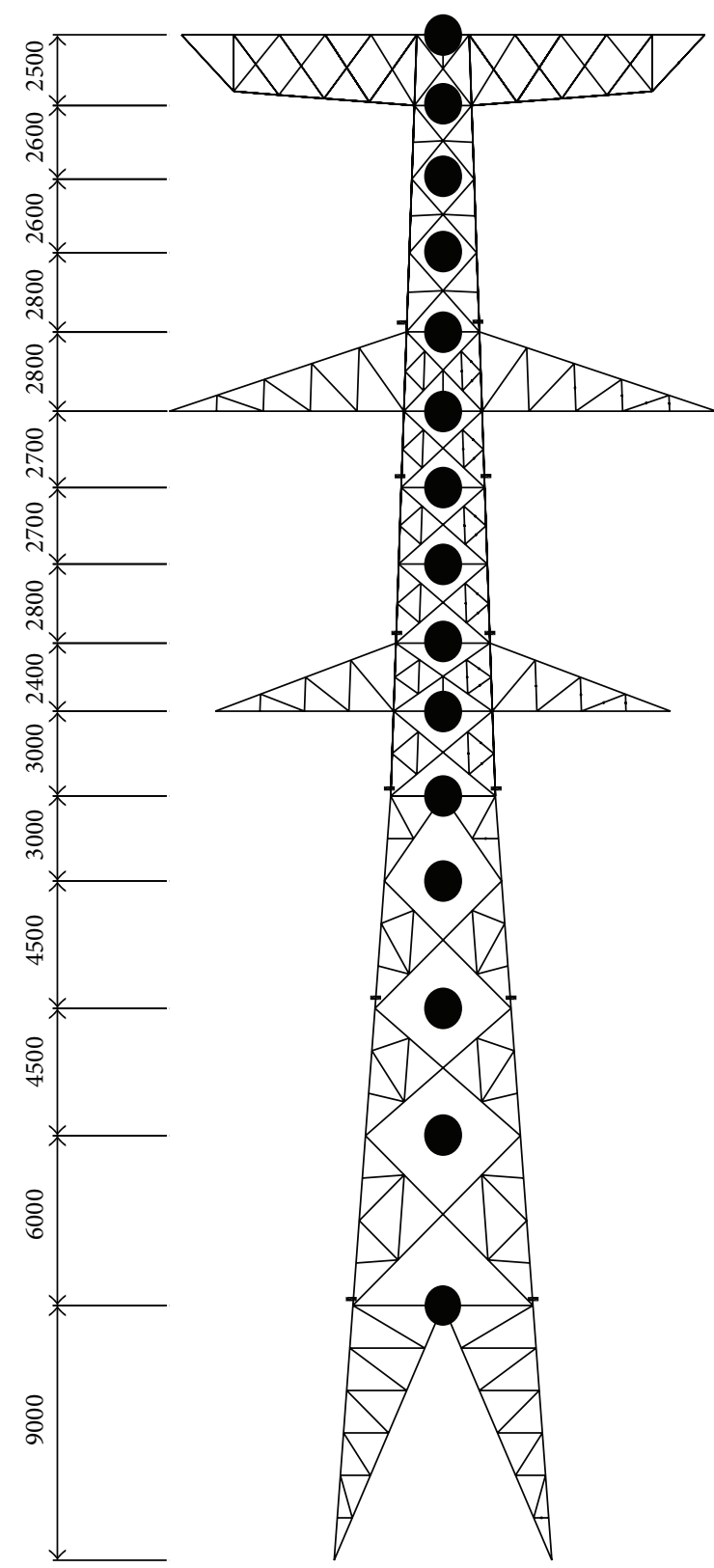

FIGURE 8: Wind simulation points.

selected as $N=8192, \Delta t=0.05$, and $\omega_{u p}=60$. The target power spectrum is Kaimal fluctuating wind power spectrum.

In order to study the influence of the wind load intensity on the vibration control performance of the SP, the mean wind velocity at the height of 10 meters above the ground $V_{10}$ is selected as $20 \mathrm{~m} / \mathrm{s}, 30 \mathrm{~m} / \mathrm{s}$, and $40 \mathrm{~m} / \mathrm{s}$.

Because the transmission tower nodes are numerous, it is difficult to simulate the wind velocity history for every node of the tower. Consequently, the transmission tower is simplified by 15 regions as shown in Figure 8 . The wind load acts only on the center of each region. The position of each region center and windward area are listed in Table 2. Similarly, each cable is divided into 10 segments. Wind load only acts on the middle of each segment. Figure 9 shows 


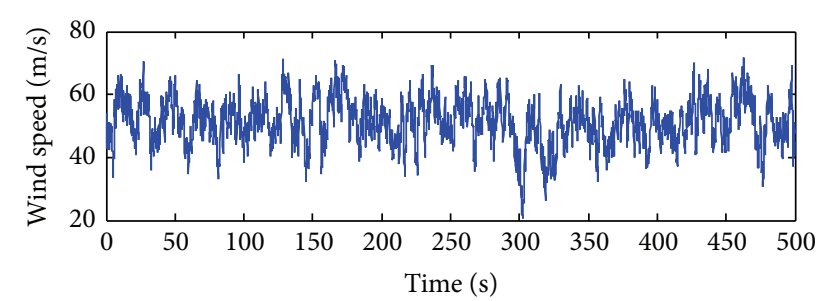

Figure 9: Time history of wind speed at the top of Tower 2, $V_{10}=$ $40 \mathrm{~m} / \mathrm{s}$.

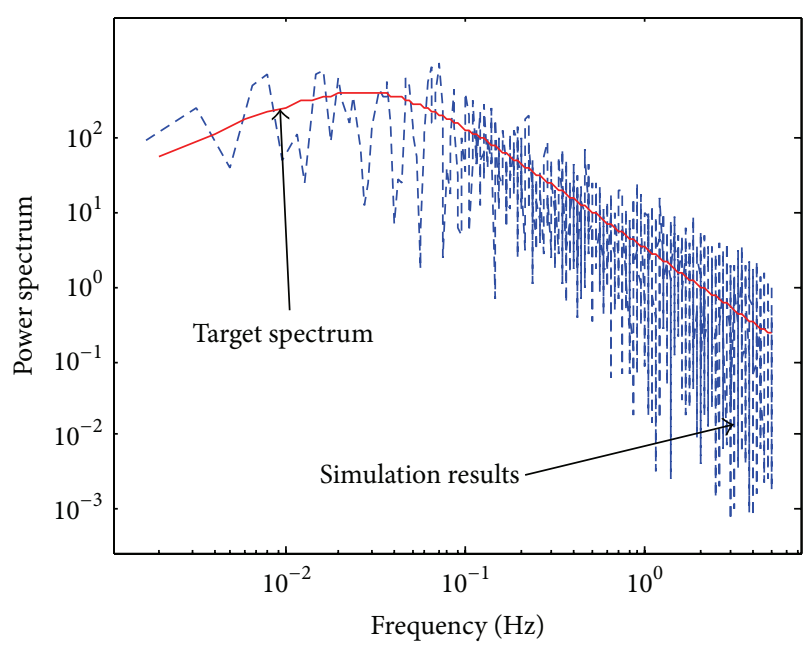

FIGURE 10: Power spectral comparison between simulated and theoretical wind samples.

the wind speed on the top of Tower 2 at $V_{10}=40 \mathrm{~m} / \mathrm{s}$ case. Figure 10 compares the target wind power spectrum and the simulated time history of the fluctuating wind. As shown in Figure 10, the simulation results agree well with the target spectrum.

3.4. Damping Consideration. Determination of the damping ratio of the power transmission tower-line system is a sophisticated problem. Damping ratio of the steel structure is usually valued $2 \%$ [27]. Moreover, the aerodynamic damping of the conductor has a significant effect on the dynamic performance [28]. According to the theory presented by Gani and Légeron [29], the aerodynamic damping can be calculated with the following equation:

$$
c(z)=\rho_{a} C_{d} \bar{v}(z) A,
$$

where $c(z)$ is the aerodynamic damping, $\rho_{a}$ is the intensity of air, $C_{d}$ is the drag coefficients, $\bar{v}(z)$ is the mean wind speed at height $z$, and $A$ is the area exposed to wind loading.

\section{Effectiveness of Vibration Reduction}

4.1. Criteria to Evaluate Vibration Control Performance. In order to verify the effectiveness of the proposed device, a SP and a SMP of the same mass ratio are designed to compare

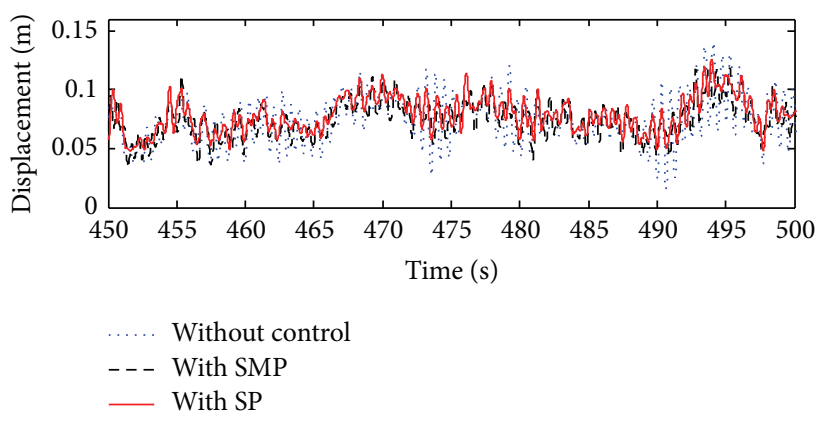

Figure 11: Displacement time history at the top of Tower 2, $V_{10}=$ $40 \mathrm{~m} / \mathrm{s}$.

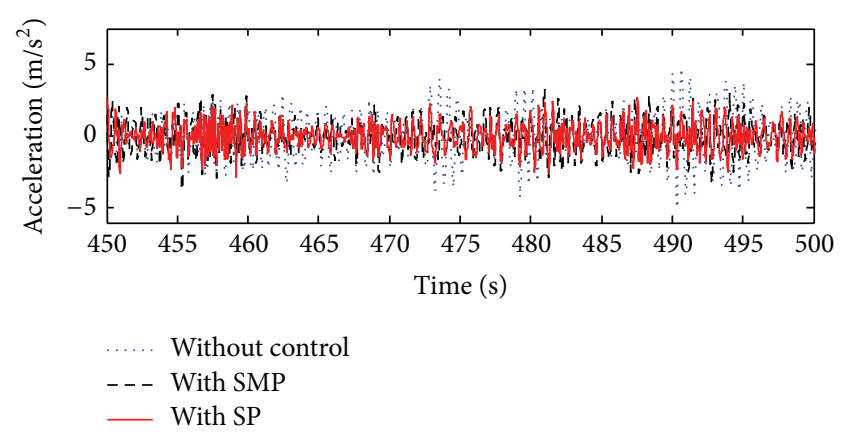

Figure 12: Acceleration time history at the top of Tower 2, $V_{10}=$ $40 \mathrm{~m} / \mathrm{s}$.

TABLE 2: The position of wind load and windward area.

\begin{tabular}{lcc}
\hline Region & $\begin{array}{c}\text { Height of the } \\
\text { region center }(\mathrm{m})\end{array}$ & $\begin{array}{c}\text { Windward } \\
\text { area }\left(\mathrm{m}^{2}\right)\end{array}$ \\
\hline 1 & 9.00 & 7.083 \\
2 & 15.0 & 4.507 \\
3 & 19.5 & 1.868 \\
4 & 24.0 & 2.435 \\
5 & 26.8 & 2.369 \\
6 & 30.0 & 2.344 \\
7 & 32.4 & 2.029 \\
8 & 35.2 & 1.672 \\
9 & 37.9 & 1.602 \\
10 & 40.6 & 1.810 \\
11 & 43.4 & 1.591 \\
12 & 46.2 & 1.117 \\
13 & 48.8 & 1.062 \\
14 & 51.4 & 1.164 \\
15 & 53.9 & 0.611 \\
\hline
\end{tabular}

their vibration control effectiveness. Here, the mass ratio is defined as follows:

$$
\mu=\frac{m}{M} \times 100 \%
$$




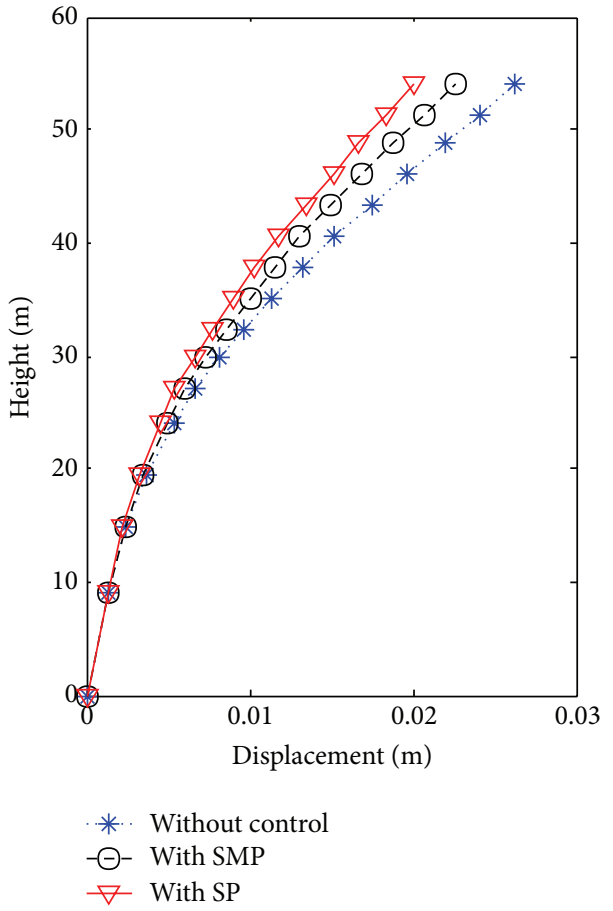

(a)

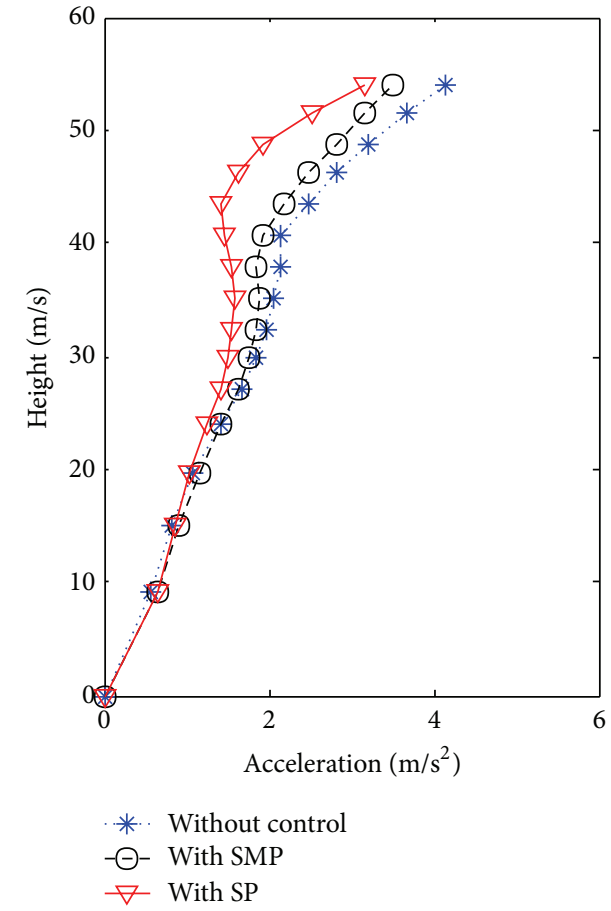

(b)

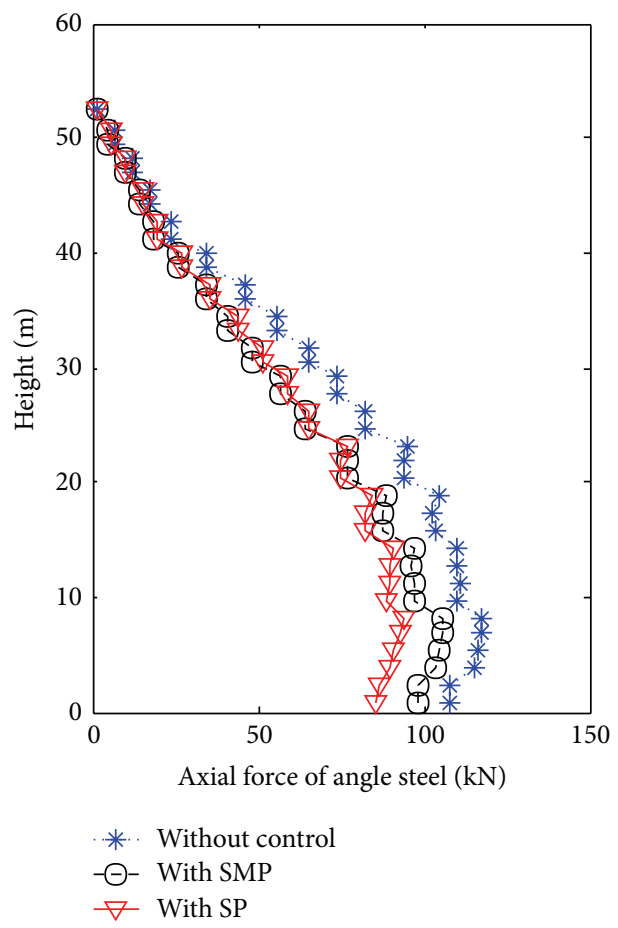

(c)

Figure 13: Envelope of (a) displacement, (b) acceleration, and (c) axial force of the $V_{10}=40 \mathrm{~m} / \mathrm{s}$ case. 
TABLE 3: Comparison of the vibration reduction ratio of SP and SMP.

\begin{tabular}{lcccccccrrr}
\hline \multirow{2}{*}{ Wind speed } & \multicolumn{2}{c}{ Max disp. } & \multicolumn{2}{c}{ Max acc. } & \multicolumn{2}{c}{ Max axial force } & \multicolumn{2}{c}{ RMS of disp. } & \multicolumn{2}{c}{ RMS of acc. } \\
& With SP & SMP & SP & SMP & SP & SMP & SP & SMP & SP & SMP \\
\hline$V_{10}=20 \mathrm{~m} / \mathrm{s}$ & $12.7 \%$ & $10.0 \%$ & $9.4 \%$ & $10.2 \%$ & $12.6 \%$ & $12.1 \%$ & $30.9 \%$ & $24.9 \%$ & $22.8 \%$ & $14.2 \%$ \\
$V_{10}=30 \mathrm{~m} / \mathrm{s}$ & $13.3 \%$ & $12.9 \%$ & $14.7 \%$ & $11.6 \%$ & $14.9 \%$ & $10.6 \%$ & $35.0 \%$ & $27.8 \%$ & $27.8 \%$ & $16.0 \%$ \\
$V_{10}=40 \mathrm{~m} / \mathrm{s}$ & $15.1 \%$ & $12.1 \%$ & $19.3 \%$ & $13.8 \%$ & $20.2 \%$ & $11.0 \%$ & $36.1 \%$ & $28.6 \%$ & $30.2 \%$ & $18.4 \%$ \\
\hline
\end{tabular}

where $\mu$ is the mass ratio, $m$ is the mass of the vibration control device, and $M$ is the mass of the power transmission tower. In this paper $\mu$ is selected to be $2 \%$.

To evaluate the vibration control effectiveness of the SP and the SMP, the vibration reduction ratio is defined as follows:

$$
\eta=\frac{r_{0}-r_{\mathrm{ctrl}}}{r_{0}} \times 100 \%
$$

where $\eta$ is the vibration reduction ratio and $r_{0}$ and $r_{\text {ctrl }}$ are the response of the tower with and without vibration control devices. $r_{0}$ and $r_{\text {ctrl }}$ can be the maximum value or the root mean square value (RMS). The maximum value can be calculated with the following equation $[28,30]$ :

$$
\widehat{r}=\bar{r}+g \widetilde{r},
$$

where $\widehat{r}$ is the peak dynamic response, $\bar{r}$ is the mean or time average response, $\widetilde{r}$ is the RMS of the fluctuating response, and $g$ is the gust response factor, generally in the range of 3-4 [28].

4.2. Comparison of Vibration Reduction Performance. Based on the numerical model and the simulated wind field, dynamic response of the power transmission tower-line system can be calculated. The time step is chosen as $0.05 \mathrm{~s}$. Figures 11-13 show the results of the $V_{10}=40 \mathrm{~m} / \mathrm{s}$ case. Results of $V_{10}=20 \mathrm{~m} / \mathrm{s}$ case and $V_{30}=30 \mathrm{~m} / \mathrm{s}$ case are very similar to that of the $V_{10}=40 \mathrm{~m} / \mathrm{s}$ case. Therefore, the figures of those two cases are omitted in this paper. The vibration reduction ratios of those two cases can be found in Table 3 .

Figures 11 and 12 compare the displacement and acceleration at the top of Tower 2 from $450 \mathrm{~s}$ to $500 \mathrm{~s}$ in the $V_{10}=$ $40 \mathrm{~m} / \mathrm{s}$ case. Figure 13 shows the envelopes of displacements, accelerations, and internal forces of Tower 2. It is clear that SP is more effective than the SMP. The SP effectively reduced the RMS value of the displacement and acceleration by $36.1 \%$ and $30.2 \%$ whereas that of the SMP is only $28.6 \%$ and $18.4 \%$, respectively. The proposed SP mitigated the maximum displacement of Tower 2 by $15.1 \%$, larger than that of the SMP, which is only $12.1 \%$. In terms of acceleration, greater effective mitigation is achieved by the SP having the maximum value reduced by $19.3 \%$. The reduction ratio of the SMP is only $13.8 \%$. In terms of axial internal force, greater effective performance has also been observed with the SP. In Figure 13(c), the largest axial internal force is reduced by the SP by $20.2 \%$, which is also larger than the reduction ratio of SMP which is $11.0 \%$.
4.3. Influence of the Wind Speed on the Vibration Reduction Performance. The SP is essentially a nonlinear damper. Thus its vibration control performance may be influenced by the intensity of external loads. Table 3 lists the vibration reduction ratio of the $\mathrm{SP}$ under 3 cases, namely, the $V_{10}=$ $20 \mathrm{~m} / \mathrm{s}$ case, the $V_{10}=30 \mathrm{~m} / \mathrm{s}$ case, and the $V_{10}=40 \mathrm{~m} / \mathrm{s}$ case. It is clear from Table 3 that the vibration performance is influenced by the level of wind loads. As the wind speed increases, the vibration reduction ratio of the SP also increases, which implies that the SP is more effective under strong winds.

This phenomenon may be explained this way: at low wind speed, the vibration of the transmission tower is small. Therefore, the SP absorbs little kinetic energy from the transmission tower and its motion is very small. The vibration of the SP is mostly in the pendulum mode. Figure 14(a) shows the locus of the SP in the $V_{10}=20 \mathrm{~m} / \mathrm{s}$. As can be seen, the SP vibrates like a linear SMP. Therefore, its vibration reduction ratio is close to that of the SMP. As the wind speed increases, the SP will vibrate more severely as it absorbs more energy. Figure 14(b) corresponds to the case of $V_{10}=40 \mathrm{~m} / \mathrm{s}$. As can be seen, the motion of the SP is larger than that of the $V_{10}=20 \mathrm{~m} / \mathrm{s}$ case, and the locus is no longer similar to that of the SMP. This implies that more energy is transmitted to the spring mode of the SP. The vibration absorbing ability is improved by the internal resonance feature.

\section{Conclusion}

This paper proposed to utilize the internal resonance feature of the SP in order to reduce the wind-induced vibration of the power transmission tower-line system. The motion equation of the spring pendulum system was obtained through Lagrangian equation. A practical transmission tower-line system was established in SAP2000 to assist numerical study. An SP and an SMP with the same mass ratio were designed to compare the vibration control performance. Based on theoretical analysis and numerical results, the following conclusions are drawn:

(1) The condition of internal resonance is verified to be $\lambda=2$. When this condition is satisfied, the pendulum mode and the spring mode of the SP will be strongly coupled and the vibration energy will be transmitted from the pendulum mode to spring mode. Consequently, the SP has larger vibration absorbing ability than the regular SMP and is more effective in reducing the vibration of the primary structure. 


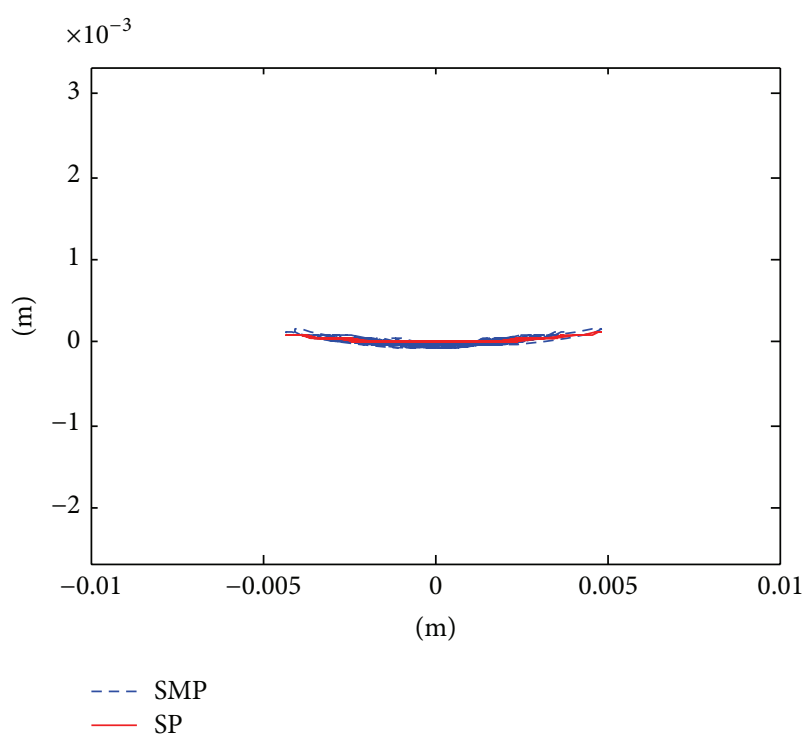

(a)

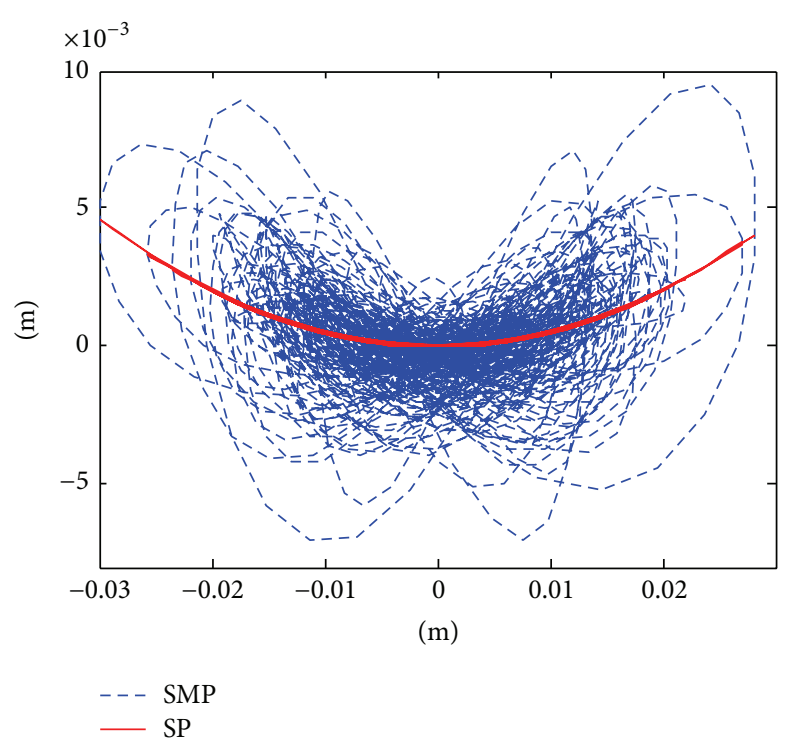

(b)

Figure 14: Locus of the SP, (a) the $V_{10}=20 \mathrm{~m} / \mathrm{s}$ case and (b) the $V_{10}=40 \mathrm{~m} / \mathrm{s}$ case.

(2) The proposed SP can be simulated using the Link element in SAP2000. The numerical results calculated by SAP2000 agree well with the theoretical results.

(3) The numerical study verified that the SP showed better vibration control performance than the regular SMP.

(4) The vibration control performance of the SP is influenced by the wind load. The SP works like a regular SMP and its vibration reduction ratio is small at low wind speed. As the wind speed increases, the internal resonance feature of the SP becomes more obvious and the vibration reduction ratio increases. This implies that the SP is more effective under larger wind loads.

\section{Conflict of Interests}

The authors declare that there is no conflict of interests regarding the publication of this paper.

\section{Acknowledgment}

This research work was supported by the Science Fund for Creative Research Groups of the National Natural Science Foundation of China (Grant no. 51121005).

\section{References}

[1] Z. Zhang, H. Li, G. Li, W. Wang, and L. Tian, "The numerical analysis of transmission tower-line system wind-induced collapsed performance," Mathematical Problems in Engineering, vol. 2013, Article ID 413275, 11 pages, 2013.

[2] J.-H. Park, B.-W. Moon, K.-W. Min, S.-K. Lee, and C. K. Kim, "Cyclic loading test of friction-type reinforcing members upgrading wind-resistant performance of transmission towers," Engineering Structures, vol. 29, no. 11, pp. 3185-3196, 2007.

[3] Q. Xie, Y. Zhang, and J. Li, "Investigation on tower collapses of $500 \mathrm{kV}$ renshang 5237 transmission line caused by downburst," Power System Technology, vol. 2006, pp. 59-63, 89, 2006.

[4] E. Savory, G. A. R. Parke, M. Zeinoddini, N. Toy, and P. Disney, "Modelling of tornado and microburst-induced wind loading and failure of a lattice transmission tower," Engineering Structures, vol. 23, no. 4, pp. 365-375, 2001.

[5] B. Chen, W.-H. Guo, P.-Y. Li, and W.-P. Xie, "Dynamic responses and vibration control of the transmission tower-line system: a state-of-the-art review," The Scientific World Journal, vol. 2014, Article ID 538457, 20 pages, 2014.

[6] C.-X. Li, J.-H. Li, and Z.-Q. Yu, "A review of wind-resistant design theories of transmission tower-line systems," Journal of Vibration and Shock, vol. 28, no. 10, pp. 15-25, 2009.

[7] J. P. Wang, B. Chen, and S. M. Sun, "Seismic response control of transmission tower-line system with friction dampers," in Proceedings of the 6th International Conference on Advances in Steel Structures and Progress in Structural Stability and Dynamics (ICASS '09), pp. 1137-1142, Hong Kong, China, December 2009.

[8] B. Chen, W.-L. Qu, and J. Zheng, "Semi-active control for windinduced responses of transmission tower-line system using friction dampers," Engineering Mechanics, vol. 26, no. 1, pp. 221226, 2009.

[9] B. Chen, J. Zheng, and W. Qu, "Control of wind-induced response of transmission tower-line system by using magnetorheological dampers," International Journal of Structural Stability and Dynamics, vol. 9, no. 4, pp. 661-685, 2009.

[10] W. Wang, D. Zhao, W. Zhong, J. Xu, J. Ling, and X. Xiao, "Effect of wind-induced vibration's control for high-voltage transmission tower based on prototype measurement," Journal of Central South University (Science and Technology), vol. 44, pp. 3911-3917, 2013. 
[11] L. Li, H. Cao, K. Ye, and Y. Jiang, "Simulation of galloping and wind-induced vibration control," Noise and Vibration Worldwide, vol. 41, no. 10, pp. 15-21, 2010.

[12] L. Li and P. Yin, "The research on wind-induced vibration control for big-span electrical transmission tower-line system," Gongcheng Lixue/Engineering Mechanics, vol. 25, no. supplement 2, pp. 213-229, 2008.

[13] S. L. Wang, X. Y. Zhu, J. Q. Zhu, J. B. Dai, and X. Zhao, "Optimal placement of GMM actuators for active vibration control of a power transmission tower," Journal of Vibration and Shock, vol. 31, no. 19, pp. 48-52, 2012.

[14] N. Kilroe, "Aerial method to mitigate vibration on transmission towers," in Proceedings of the IEEE 9th International Confernce on Trasmission and Distribution Construction, Operation and Live-Line Maintenance Proceedings (ESMO '00), pp. 187-194, Montreal, Canada, 2000.

[15] R. C. Battista, R. S. Rodrigues, and M. S. Pfeil, "Dynamic behavior and stability of transmission line towers under wind forces," Journal of Wind Engineering and Industrial Aerodynamics, vol. 91, no. 8, pp. 1051-1067, 2003.

[16] G. H. Liu and H. N. Li, "Analysis and optimization control of wind-induced dynamic response for high-voltage transmission tower-line system," Proceedings of the Chinese Society of Electrical Engineering, vol. 28, no. 19, pp. 131-137, 2008.

[17] Y. He, W. Lou, B. Sun, S. Yu, Y. Guo, and Y. Ye, "Windinduced vibration control of long span transmission tower with suspended mass pendulums," Journal of Zhejiang University (Engineering Science), vol. 39, pp. 1891-1896, 2005.

[18] A. F. Vakakis, "Inducing passive nonlinear energy sinks in vibrating systems," Journal of Vibration and Acoustics, Transactions of the ASME, vol. 123, no. 3, pp. 324-332, 2001.

[19] X. Jiang, D. Michael Mcfarland, L. A. Bergman, and A. F. Vakakis, "Steady state passive nonlinear energy pumping in coupled oscillators: theoretical and experimental results," Nonlinear Dynamics, vol. 33, no. 1, pp. 87-102, 2003.

[20] P. Zhang, G. Song, H.-N. Li, and Y.-X. Lin, "Seismic control of power transmission tower using pounding TMD," Journal of Engineering Mechanics, vol. 139, no. 10, pp. 1395-1406, 2013.

[21] Y.-C. Zhang, X.-R. Kong, Z.-X. Yang, and H.-L. Zhang, “Targeted energy transfer and parameter design of a nonlinear vibration absorber," Journal of Vibration Engineering, vol. 24, no. 2, pp. 111-117, 2011.

[22] Z. B. Yang, Q. H. Xia, and S. P. Liu, "The spring pendulum under different controlled parameters," College Physics, no. 5, pp. 2326, 42, 2011.

[23] J. P. Wang, H. Z. Liu, D. N. Yuan, and Z. X. Xu, "An improved state space model for parts of nonlinear oscillation systems and its numerical method," Chinese Journal of Applied Mechanics, vol. 112, pp. 116-167, 2002.

[24] X. Zhang, Handbook of Wind Load Thories and Wind-Resistant Computations for Engineering Structures, Tongji University Press, Shanghai, China, 1990.

[25] M. Shinozuka and C.-M. Jan, "Digital simulation of random processes and its applications," Journal of Sound and Vibration, vol. 25, no. 1, pp. 111-128, 1972.

[26] H.-N. Li, T.-H. Yi, Q.-Y. Jing, L.-S. Huo, and G.-X. Wang, "Wind-induced vibration control of Dalian international trade mansion by tuned liquid dampers," Mathematical Problems in Engineering, vol. 2012, Article ID 848031, 21 pages, 2012.

[27] J. Yang, F. Yang, Q. Li, D. Fu, and Z. Zhang, "Dynamic responses analysis and disaster prevention of transmission line under strong wind," in Proceedings of the Interntional Conference on Power System Technology, pp. 1-6, IEEE, October 2010.

[28] A. M. Loredo-Souza and A. G. Davenport, "The effects of high winds on transmission lines," Journal of Wind Engineering and Industrial Aerodynamics, vol. 74-76, pp. 987-994, 1998.

[29] F. Gani and F. Légeron, "Dynamic response of transmission lines guyed towers under wind loading," Canadian Journal of Civil Engineering, vol. 37, no. 3, pp. 450-464, 2010.

[30] H. Yasui, H. Marukawa, Y. Momomura, and T. Ohkuma, "Analytical study on wind-induced vibration of power transmission towers," Journal of Wind Engineering \& Industrial Aerodynamics, vol. 83, pp. 431-441, 1999. 


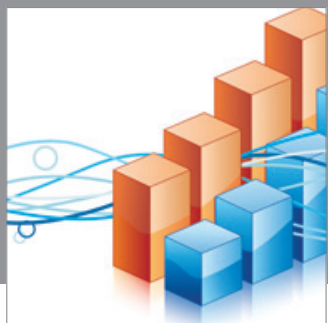

Advances in

Operations Research

mansans

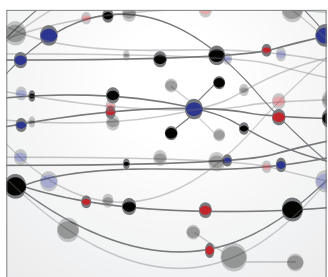

The Scientific World Journal
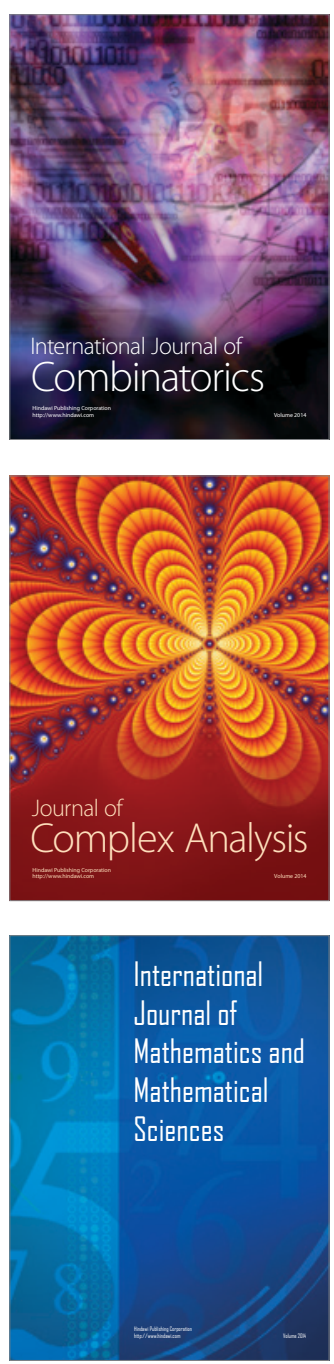
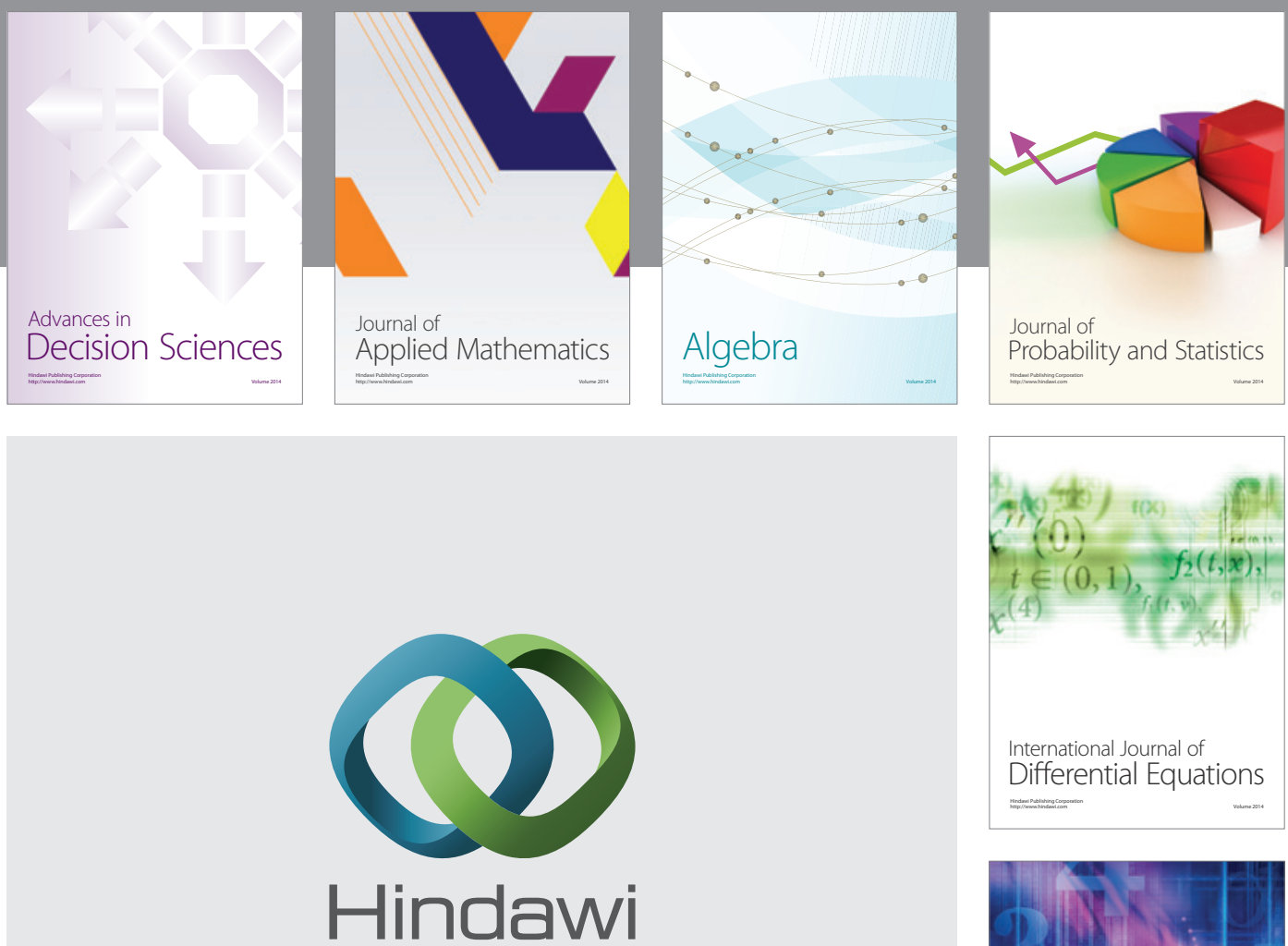

Submit your manuscripts at http://www.hindawi.com
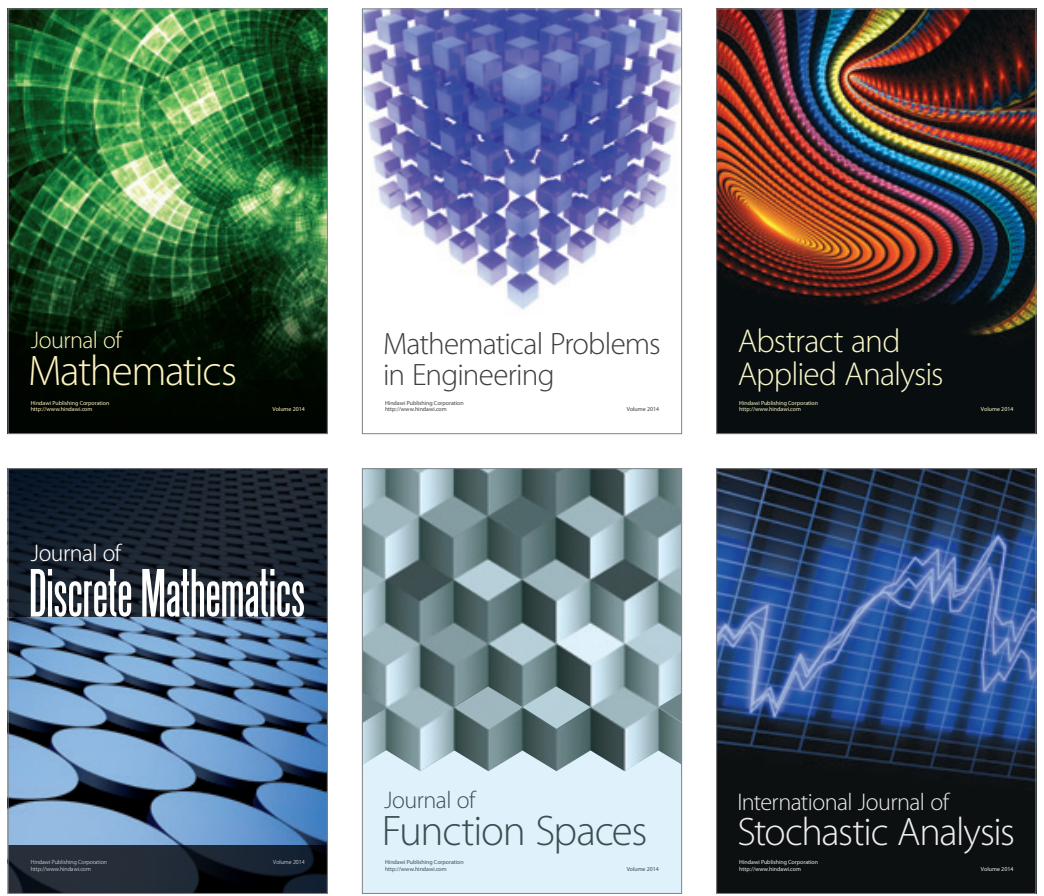

Journal of

Function Spaces

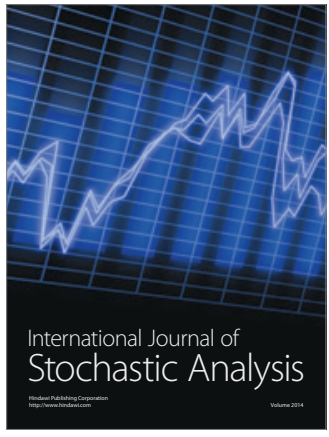

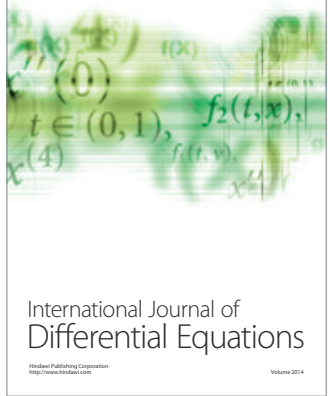
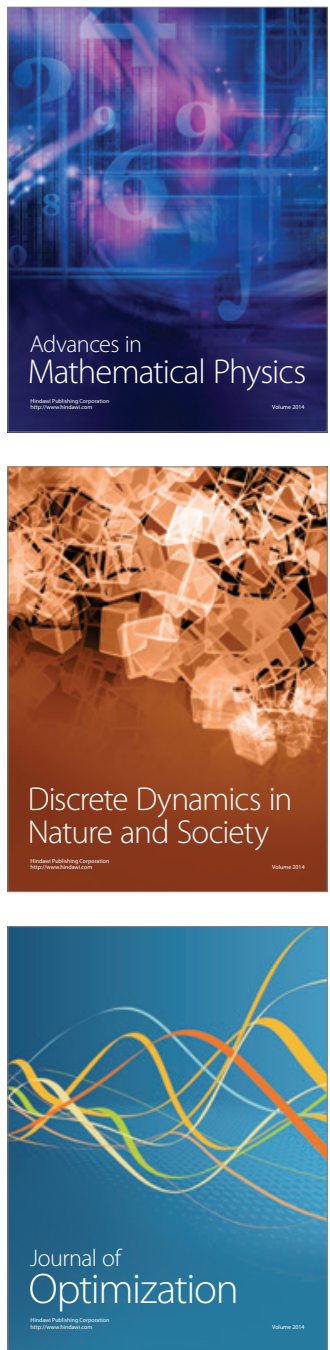